Linguagem em (Dis)curso, Palhoça, SC, v. 9, n. 3, p. 441-461, set./dez. 2009

\title{
COMPUTADORES E ENSINO DE LÍNGUAS ESTRANGEIRAS: UMA ANÁLISE DE SITES INSTRUCIONAIS
}

Antonia Dilamar Araújo*

Resumo: Este artigo tem por objetivo examinar e refletir sobre as atividades propostas para o desenvolvimento das habilidades de leitura e escrita disponíveis em websites na Internet e que podem ser usadas como complemento do ensino presencial em sala de aula de língua inglesa. Com base em critérios estabelecidos por estudiosos de novas tecnologias aplicadas à educação, pretendeu-se avaliar a qualidade desses materiais instrucionais. De 25 websites em língua inglesa selecionados, 15 foram analisados detalhadamente com foco nas atividades de leitura e escrita. Os resultados revelam que há pouca variedade das atividades de leitura e escrita nos materiais da web e que não há diferenças entre as propostas de atividades dos websites educacionais e as apresentadas nos livros didáticos impressos..

Palavras-chave: internet; sites educacionais; material didático; ensino de língua inglesa.

\section{INTRODUÇÃO}

Uma das exigências da vida moderna é a aquisição de uma língua estrangeira, em especial, a língua inglesa - língua franca de comunicação mundial - e de habilidades específicas para uso do computador com seus recursos na Internet. Neste novo milênio, para se ter participação efetiva nas diferentes atividades na sociedade e para se ter ascensão social, não só é necessário indivíduos possuírem letramento tradicional, como também o letramento digital, que significa a aquisição de habilidades e

\footnotetext{
* Professora de Língua Inglesa e Linguística Aplicada da Universidade Estadual do Ceará, Fortaleza, Ceará, Brasil. Doutora em Letras e Linguística Aplicada. Email: <dilamar@gmail.com>.
} 


\section{2}

competências no uso de novas tecnologias para se comunicar. A questão é: como os aprendizes estão sendo letrados em uma segunda língua em ambientes mediados por computador nas escolas? Que materiais instrucionais na web são disponibilizados para ensino de línguas estrangeiras e utilizados nas escolas? Qual a qualidade desses materiais para uma aprendizagem eficaz de língua estrangeira?

A utilização de tecnologias na educação tem motivado pesquisadores a estudarem o impacto e as mudanças que estão ocorrendo no processo ensino-aprendizagem examinando não só as práticas de uso da linguagem, mas também as práticas de se ensinar com novas tecnologias. Este artigo tem por objetivo refletir sobre os websites educacionais para aprendizagem de língua inglesa disponíveis na Internet, no sentido de avaliar a qualidade das atividades propostas para as habilidades de leitura e escrita e sua contribuição para o processo de aprendizagem de uma língua estrangeira.

\section{NOÇÃO DE LETRAMENTO DIGITAL}

O advento da Internet e as mudanças nas práticas socioculturais dos indivíduos têm suscitado considerável discussão nos anos recentes deste novo milênio sobre o que significa ser letrado. Kress (2003) afirma que a transição do texto impresso para a tela do computador revela que ser "letrado" é um conceito líquido e que exige uma revisão contínua de métodos pedagógicos. $\mathrm{Na}$ discussão do que significa ser letrado na sociedade pós-moderna, vale lembrar os conceitos de Street (1984), Barton e Hamilton (1998), Shetzer e Warschauer (2000) e Snyder (2000). Brian Street (1984), com sua noção sociocultural de letramento, defende que letramento é mais do que a capacidade de decodificar para compreender sentidos inscritos em uma página impressa, na tela do computador, ou ainda, em uma prática social situada. Esta visão tem influenciado muitos estudiosos de letramento. Barton e Hamilton (1998), que também compartilha a idéia de que letramento é uma prática cultural, sócio e historicamente estabelecida, considera que o letramento permite ao indivíduo apoderar-se de um conjunto de habilidades e conhecimento e participar efetivamente de todos os eventos da 
comunidade a que pertence e das tradições, hábitos e costumes com os quais se identifica. Ao examinar contextos de ensino e aprendizagem de línguas, Shetzer e Warschauer (2000) consideram que o indivíduo é "letrado eletronicamente" quando adquire a habilidade para construir sentidos da informação a que tem sido exposto na tela do computador considerando as práticas de "aprendizagem de como ler e escrever nesse novo meio" (p. 173). Para Snyder (2000), ser letrado "também envolve a capacidade e disposição de escrutinizar práticas e universos de significados em textos que são imbricados" (p. 105, tradução minha). É o chamado "letramento tecnológico". Esta visão de letramento tecnológico associado à aprendizagem vista como prática social, segundo Snyder, compreende três dimensões: operacional, cultural e crítica.

A dimensão operacional para educação envolve o uso de novas tecnologias, focaliza tanto como operar o sistema de linguagem, como também o sistema da tecnologia. Entender e ser capaz de realizar a dimensão cultural de letramento envolve compreender a habilidade de operar sistemas de língua e tecnologia a serviço de participar de formas autênticas de prática social, considerando que as pessoas sempre usam textos e tecnologias para fazer coisas no mundo e para alcançar seus próprios propósitos e os dos outros, seja no contexto da escola, do trabalho ou da vida diária. Isto significa colocar ênfase nos contextos autênticos, formas e propósitos reais de aprendizagem ao longo dos eixos letramento e tecnologia e texto e informação (CASTANHEIRA; GREEN; DIXON, 2007). Já a dimensão crítica significa que professores e estudantes necessitam ser capazes de avaliar softwares e outros recursos tecnológicos com um espírito de ceticismo informado. Eles precisam saber usar tais recursos e participar efetivamente e criativamente em suas culturas, mas também saber usá-los e criticá-los para contribuir na transformação de práticas sociais quando julgarem adequado.

Estas três dimensões são importantes para se entender como as novas práticas de ler e escrever estão afetando o letramento, a tecnologia, a aprendizagem e o relacionamento entre elas. Como o interesse deste trabalho é a avaliação de materiais didáticos on-line como recursos que contribuem para o letramento eletrônico e linguístico de aprendizes de uma língua estrangeira (doravante LE), a dimensão crítica parece ser importante para desenvolver uma consciência por parte dos professores na escolha dos materiais adequados para seu alunos. 


\section{WEBSITES EDUCACIONAIS COMO FONTES DE APRENDIZAGEM DE LÍNGUAS}

Embora o acesso à Internet não seja ainda plenamente democrático no Brasil, é inegável o reconhecimento das vantagens da rede em facilitar a comunicação e acesso à informação em todos os campos profissionais, incluindo a instrução de línguas, quer seja materna, quer seja estrangeira (BRANDL, 2002; LEE, 2002, on-line). Entre as principais vantagens apontadas pelos autores estão a disponibilidade e acesso a materiais autênticos ${ }^{1}$, a comunicação em rede, a estrutura não linear da informação. Nos anos recentes, o uso da web como uma fonte de materiais para ensino e aprendizagem de língua têm se expandido e começado a se popularizar entre professores de línguas, porém pouca pesquisa empírica tem sido realizada que demonstre que o uso efetivo desses materiais nos ambientes multimídia produza resultados satisfatórios no que diz respeito ao letramento na língua estrangeira e como esses materiais são avaliados. Somente na metade da década de 90 a Internet começou a ser considerada como um meio adequado para aprendizagem em geral e aprendizagem de línguas, em particular. Nesta perspectiva, a aprendizagem mediada por computador tem sido considerada para examinar como a Internet pode criar um ambiente de aprendizagem no qual os aprendizes podem ganhar competência linguística e cultural na língua-alvo e como a aplicação de atividades na Internet pode apoiar as perspectivas teóricas e os princípios de aprendizagem de línguas estrangeiras. Assim, páginas educacionais baseadas na web têm começado a surgir, algumas gratuitas, outros pagas, disponibilizando atividades para aprendizagem de línguas a qualquer indivíduo interessado na aquisição de conhecimento através de materiais autênticos, como também páginas destinadas a professores com orientações e sugestões de ensino sobre as diferentes habilidades e tópicos. Tais materiais, além de aumentar a exposição do aluno à linguagem em língua estrangeira, servem de apoio para executar certas atividades que gerarão novas interações e novas tarefas de aprendizagem.

\footnotetext{
1 'Materiais autênticos' significa o uso na sala de aula de textos, vídeos, fotografias e outras fontes usadas na comunicação genuína da vida real e que não foram especialmente preparadas para propósitos pedagógicos (RICHARDS, 2001, p. 252).
}

ARAÚJO - Computadores e ensino de línguas estrangeiras... 
Educadores têm começado a se interessar não somente pelo uso de fontes existentes na web na sala de aula ou como atividade extraclasse, mas também pelo design, implementação, testagem e avaliação de materiais em ambiente virtual. Dentre os estudiosos em avaliação de materiais on-line destaco: Smith (1997); Barnes e Murray (1998); Kelly (2000); Román (2002); Freire et al. (2004), Stapleton e Helms-Park (2006), apenas para citar alguns, que propuseram instrumentos de avaliação para fontes de informação na web. Esses autores reconhecem que critérios como o uso da língua, layout e recursos visuais, usabilidade, utilidade, autenticidade de linguagem, forma do feedback, facilidade de navegação, são aspectos que devem ser considerados na avaliação da qualidade de websites com fins educacionais. Autores também têm sugerido examinar a credibilidade de autoria dos sites como um critério avaliativo. No que diz respeito ao design, Zorko (2007) planejou e aplicou materiais multimídias com estudantes de segundo ano de Sociologia em um curso de Inglês para Propósitos acadêmicos na universidade da Slovênia para desenvolver a aprendizagem autônoma mediada por computador. Os materiais usados provaram ser úteis e estimulantes para os alunos que interagiram com textos, imagens, áudio e vídeo na aprendizagem da língua inglesa, desenvolvendo habilidades de compreensão de palestras, participação em discussões em classe, leitura de textos autênticos, escrita de e-mails. Os materiais ainda deram a oportunidade aos alunos de se engajarem em comunicação autêntica e se familiarizarem com recursos on-line, usando-os de forma independente.

Uma questão central que nos chama a atenção, e de interesse neste estudo, é a qualidade dos materiais disponíveis na Internet, que antes de serem usados ou recomendados pelo professor devem ser examinados com critérios estabelecidos previamente e tomando por base a teoria de aprendizagem adotada pelos professores. Em acréscimo, há também o desafio do professor de saber implementar atividades especificamente para a web ou de selecionar materiais educacionais adequados para desenvolver as habilidades de leitura e escrita dos alunos. Para realizar tais tarefas, o profissional da educação deve ter conhecimento mais amplo de teorias de aprendizagem de línguas e habilidades desenvolvidas para uso do ambiente $W e b$.

Websites educacionais bem planejados podem facilitar a interação entre leitores e textos e, por conseguinte, estimular a compreensão e o 
desenvolvimento de habilidades de leitura crítica e escrita. Seguir links em subsequentes sessões on-line encoraja os leitores estudantes a desenvolverem estratégias de como abordar o conteúdo do texto e ativar esquemas para interpretar o conteúdo desse texto e construir sentidos. Kasper (2000) sugere que a leitura de hipertexto é um processo dinâmico, recursivo e integrado que oferece oportunidades para os estudantes adquirirem, testarem e reformularem o conhecimento através da reconstrução cognitiva do texto, da análise intertextual e exposição a variadas perspectivas sobre determinado assunto. Assim, o website com forma hipertextual pode promover a compreensão através da elaboração e integração de informação nova à já existente quando os leitores criam e expandem o mapa cognitivo que guia sua construção de sentidos. Warshauer (1997) recomenda que as atividades de comunicação mediada pelo computador sejam experienciais, orientadas pelos objetivos de ensino e consistentes com os princípios da aprendizagem situada, isto é, os alunos devem engajar-se em tarefas significativas e de solução de problemas que são de seu interesse. Zorko (2007) também acrescenta que as atividades para aprendizagem na web devem permitir aos estudantes construírem seu próprio conhecimento livremente e encorajar o desenvolvimento de suas visões pessoais sobre os tópicos estudados.

Este estudo objetiva avaliar as atividades propostas para o desenvolvimento das habilidades de leitura e escrita disponíveis em websites na Internet e que podem ser usadas como complemento do ensino presencial em sala de aula de língua inglesa, com base em critérios estabelecidos.

\section{ANÁLISE DE PROPOSTAS DE ATIVIDADES PARA LEITURA E ESCRITA EM WEBSITES EDUCACIONAIS}

\subsection{Critérios de análise}

Este trabalho é parte do projeto de pesquisa intitulado "Texto eletrônico e letramento: uma análise das habilidades de leitura e produção escrita em sites educacionais em língua inglesa", em fase de conclusão na UECE, (2005-2009), que objetivou tanto o 
acompanhamento do ensino de língua inglesa com novas tecnologias de uma escola particular de ensino fundamental e médio de Fortaleza quanto a análise de atividades propostas para aprendizagem de leitura e de escrita em websites instrucionais de LI (língua inglesa), como fonte de material complementar ao ensino presencial. Para os propósitos deste artigo, examinamos apenas a qualidade das propostas de atividades didático-pedagógicas dos websites educacionais, como forma de verificar como elas contribuem para o letramento em língua estrangeira.

Para a análise das atividades de leitura e escrita, selecionou-se 25 sites educacionais gratuitos destinados ao ensino da língua inglesa para uma avaliação geral e para identificação daqueles que apresentam atividades de leitura e escrita. Os sites foram analisados segundo os critérios de: estrutura e organização, público-alvo (aluno, professor ou ambos), conteúdo, objetivo, recursos interativos e usabilidade (facilidade de uso e navegação). Dos 25 websites identificados, apenas quinze foram selecionados para análise mais detalhada das atividades de leitura e escrita.

Os sites educacionais analisados foram:

- www.bbc.co.uk/skillswise/words/reading,

- www.better-english.com,

- http://www.englishclub.com

- www.towerofenglish.com

- www.englishpage.com

- www.learnerEnglishfeelgood.com

- www.english-zone.com

- www.esl4kids.com
- www.readingmatrix.com/directory/ pages/Reading_Comprehension,

- www.englishbaby.com

- www.learnerenglish.org.uk

- www.usingenglish.com

- www.eslcafe.com

- www.English-at-home.com

- www.eslflow.com

A análise das atividades foi baseada em critérios tais como: objetivo, instrução da atividade (clareza), usabilidade, conteúdo (informação original e atualizada, quantidade de links), formato da atividade, interatividade, feedback (tipo de feedback fornecido) e teoria que embasa a atividade. Para uma atividade ser considerada qualitativamente adequada para a aprendizagem, ela deve atender pelo menos de 5 a 8 dos critérios; regular, de 3 a 4 critérios, e não adequadas, de 0 a 2 critérios. 


\section{8}

\subsection{Resultados da análise dos materiais}

Em uma análise geral, observou-se que, quanto à estrutura e organização, os sites podem ser classificados em três grupos:

a) sites com links internos - aqueles cujas páginas são elaboradas pelo próprio autor ou instituição, por exemplo, English-at-home, www.bbc.co.uk;

b) sites com links externos - aqueles que remetem o leitor a outro website, por exemplo, tower of English, ESL-resource.info, ou ainda;

c) do tipo misto - quando possuem os dois tipos de links, internos e externos; por exemplo, www.eslcafe.com.

No que diz respeito aos objetivos dos websites, percebeu-se que há sites institucionais (por exemplo, readingmatrix.com), cujo objetivo é divulgar o trabalho de uma instituição; sites comerciais, que têm o objetivo de fazer propaganda de produtos como materiais didáticos e cursos (por exemplo, englishclub) e os educacionais, que, embora limitados em seu conteúdo, trazem links com atividades para ensino e aprendizagem da língua inglesa (por exemplo, bbc.co.uk, johnsesl.com, towerofenglish.com, English-at-home.com, Learnerenglishfeelgood.com, english-zone.com).

Quanto ao conteúdo para ensino de língua inglesa, observou-se que os sites são limitados. Alguns apresentam atividades de gramática e vocabulário; outros objetivam desenvolver habilidades de leitura, compreensão oral (atividades de listening) e expressão escrita; outros focalizam vocabulário, cultura, expressões idiomáticas e slangs (gírias). Poucos desenvolvem a expressão oral, devido à dificuldade de se ter um professor virtual para interagir, acompanhar o trabalho do aluno e dar feedback imediato. Os websites com foco na habilidade oral, em geral, são pagos e o usuário precisa se cadastrar e ter uma senha para acessá-los (ex: Englishtown.com.br). Com relação aos recursos interativos, as atividades planejadas mostram que a interação se dá, em geral, entre o aluno e a máquina, poucas são as atividades que estimulem os aprendizes a interagir virtualmente com outros usuários. Nesse aspecto, vale ressaltar que os recursos interativos mais utilizados nos sites são o chat, o e-mail e o 
fórum de discussões. No entanto, é importante dizer que estes websites apresentam conteúdo coerente com seus objetivos e adequados ao público-alvo. Quanto à usabilidade, os sites são de fácil acesso e navegação rápida e simples. Os linkes são constituídos de linguagem verbal mais do que não-verbal. Os usuários precisam ter apenas habilidades mínimas de informática para fazer uso dos sites de forma satisfatória.

Apesar ainda da limitação dos sites, o seu uso como conjunto de materiais didáticos na sala de aula de língua estrangeira tem sido reconhecido por autores como Meloni (1998) e Moote (2002), que chamam a atenção dos professores para o aspecto motivador desse material on-line para o aprendizado dos alunos, além de desenvolver a autonomia. Os autores sugerem que, ao se fazer escolhas, considere-se nessa análise: autoria, carga cognitiva, facilidade de uso e navegação, apresentação e conteúdo da informação, propósito, integração de multimídia, funcionalidade, tipo de interação permitida. Souza (2004), ao reconhecer que o ensino de línguas mediado por computador ainda não é baseado em um perspecitva sociointeracionista e que se precisa definir mais claramente os paradigmas de integração e desenvolvimento de CALL no Brasil, o fato de este já estar sendo introduzido nos contextos escolares brasileiros deve ser visto como fator positivo. No entender do autor, corroborando a visão de Bax (2003), há necessidade de "uma real integração do computador nas salas de aula e nos currículos de ensino de línguas estrangeiras" (SOUZA, 2004, p. 83).

Estes websites, por terem a natureza de portal, são estruturados em sessões com hiperlinks que incluem, além das atividades pedagógicas, propaganda de cursos de línguas, materiais didáticos, e até de outros websites educacionais, enquanto poucos websites são construídos apenas com links internos contendo atividades de gramática, vocabulário, compreensão oral, pronúncia, leitura e escrita. Estes últimos são o foco de análise neste estudo.

Uma análise mais detalhada dos websites revelou que a maioria das atividades propostas assemelha-se àquelas apresentadas em livros didáticos impressos, com a diferença de que as atividades estão ancoradas em um novo ambiente de aprendizagem ou suporte: a web. A semelhança se percebe, principalmente, na teoria que embasa as 
atividades, dado que estas não são desenhadas em uma metodologia comunicativa e colaborativa, mas seguem, na grande maioria, o modelo estrutural/audiolingual de base behaviorista.

$\mathrm{Na}$ análise, pode-se perceber que o objetivo das atividades, embora não seja apresentado de forma explícita, é o de desenvolver a habilidade de leitura e o de consolidar vocabulário e gramática através da escrita. O formato das atividades, em geral, é padronizado. No desenvolvimento da habilidade de leitura, há um texto seguido de questões de compreensão em formato de múltipla escolha em que o aprendiz tem que escolher uma resposta correta. Neste aspecto, a abordagem é estrutural, guiada e controlada. Essas atividades podem ser consideradas, na perspectiva de Brandl (2002), como centradas no professor, pois este controla toda a situação e o processo de aprendizagem. Assim, a maioria das atividades de leitura dos sites pode ser classificada como tendo características desta abordagem. Três sites que vale destacar por fugirem deste paradigma são o readingmatrix.com, usingenglish.com (gratuítos) e Englishtown (pago), cujas atividades de leitura apresentam formato diferente dos demais. Em geral apresentam um texto e questões de compreensão abertas para serem respondidas discursivamente ou com textos lacunados para preenchimento com vocabulário para completar o sentido. Tais atividades são desafiantes para o desenvolvimento cognitivo do aprendiz e levam o aluno a buscar soluções para os problemas propostos na leitura e na escrita. $\mathrm{O}$ site da BBC (versão 2005), embora limitado, com poucas atividades, é atualizado com frequência e apresenta um padrão de atividades para desenvolver as habilidades dos alunos através de estratégias básicas de leitura como skimming, scanning, vocabulário e tipos textuais, como se pode ver na figura 1. $\mathrm{Na}$ versão 2007, o resumo foi acrescentado. As atividades são apresentadas em três níveis de dificuldade (iniciantes, intermediários e avançados); o aluno escolhe aquela que se adeque ao seu nível de conhecimento de língua para explorar.

No site da BBC, tanto as habilidades de leitura como as de escrita apresentam seções padronizadas, no total de cinco, iniciando com start, seguida por factsheet, que traz explicações sobre o significado de cada estratégia, além de quizzes, jogos e exercícos que complementam a prática da leitura e da escrita. Vale a pena observar que, apesar de as seções serem marcadas por uma seta, que indica a direção que o aluno deve seguir para 
aprender a ler ou escrever segundo a habilidade em foco, o aluno tem a liberdade para traçar a sua trajetória de aprendizagem.

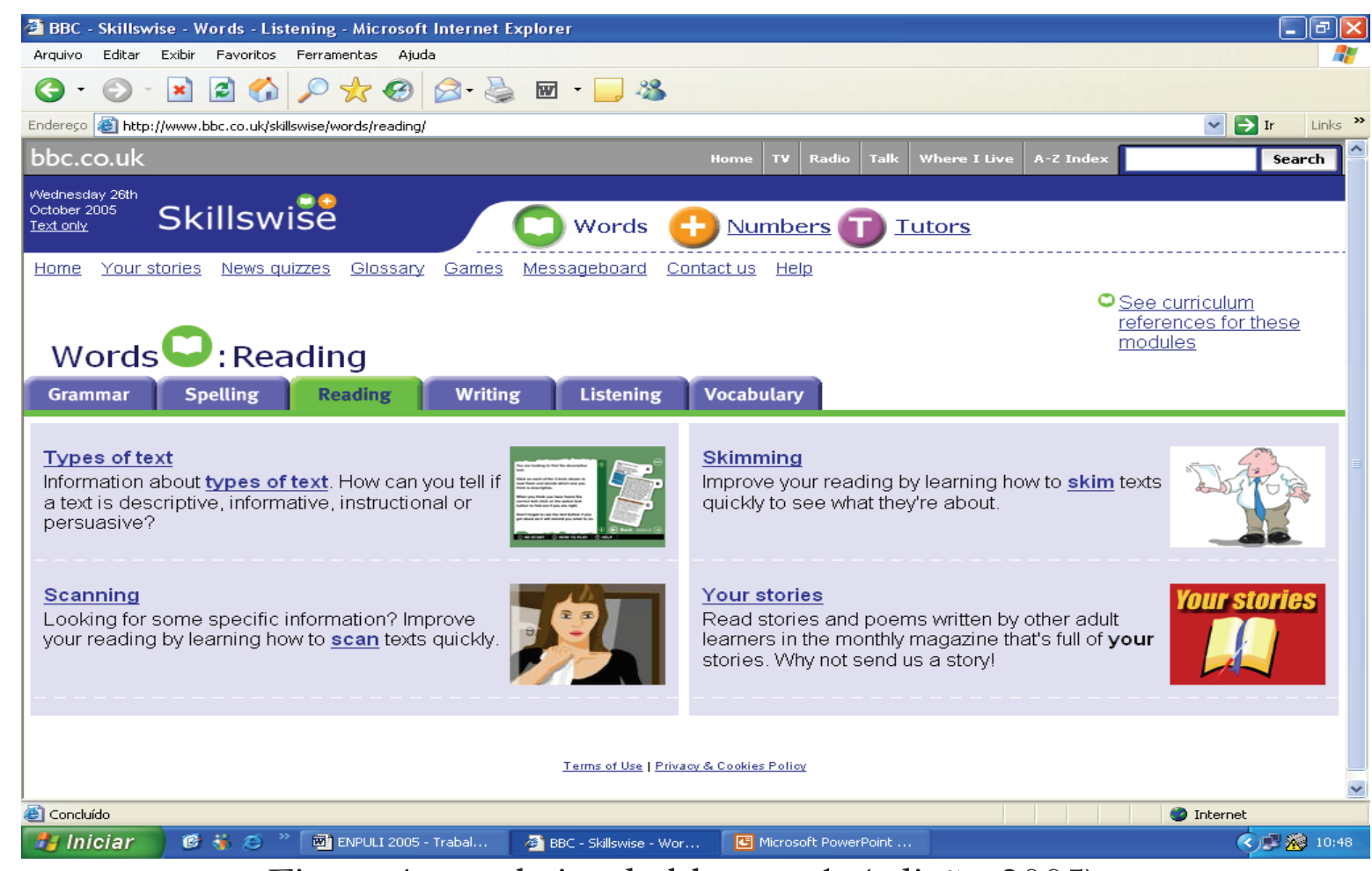

Figura 1 - website da bbc.co.uk (edição 2005).

Um aspecto importante no processo ensino-aprendizagem é o feedback. Nas interações on-line, o feedback exerce um papel relevante que é o de informar sobre o desempenho acadêmico do aluno ou do professor (feedback avaliativo). Feedback no contexto on-line pode ser entendido como resposta à presença de alguma ação com o objetivo de avaliar ou medir o desempenho no processo de ensino-aprendizagem quando o aluno interage com a máquina (PAIVA, on-line). O aluno necessita de feedback efetivo para as respostas dadas nos exercícios. $\mathrm{Na}$ análise das atividades dos sites, pude observar três tipos de feedback:

a) imediato e quantitativo, em que, ao final da tarefa, os alunos tomam conhecimento de quantos scores acertaram ou erraram;

b) imediato com comentário: no final da tarefa os alunos, além de tomarem conhecimento dos scores, recebem os comentários sobre a resposta correta e por que ela é correta; e 
c) resposta escrita, enviada por e-mail, a um interlocutor ou professor virtual para correção. No site da BBC, o feedback é dado de forma imediata com comentário no final da atividade. $\mathrm{O}$ aluno conhece quantos scores acertou na compreensão do texto. Exemplo (ver figuras 2 e 3 ).

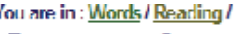 \\ Scanning}

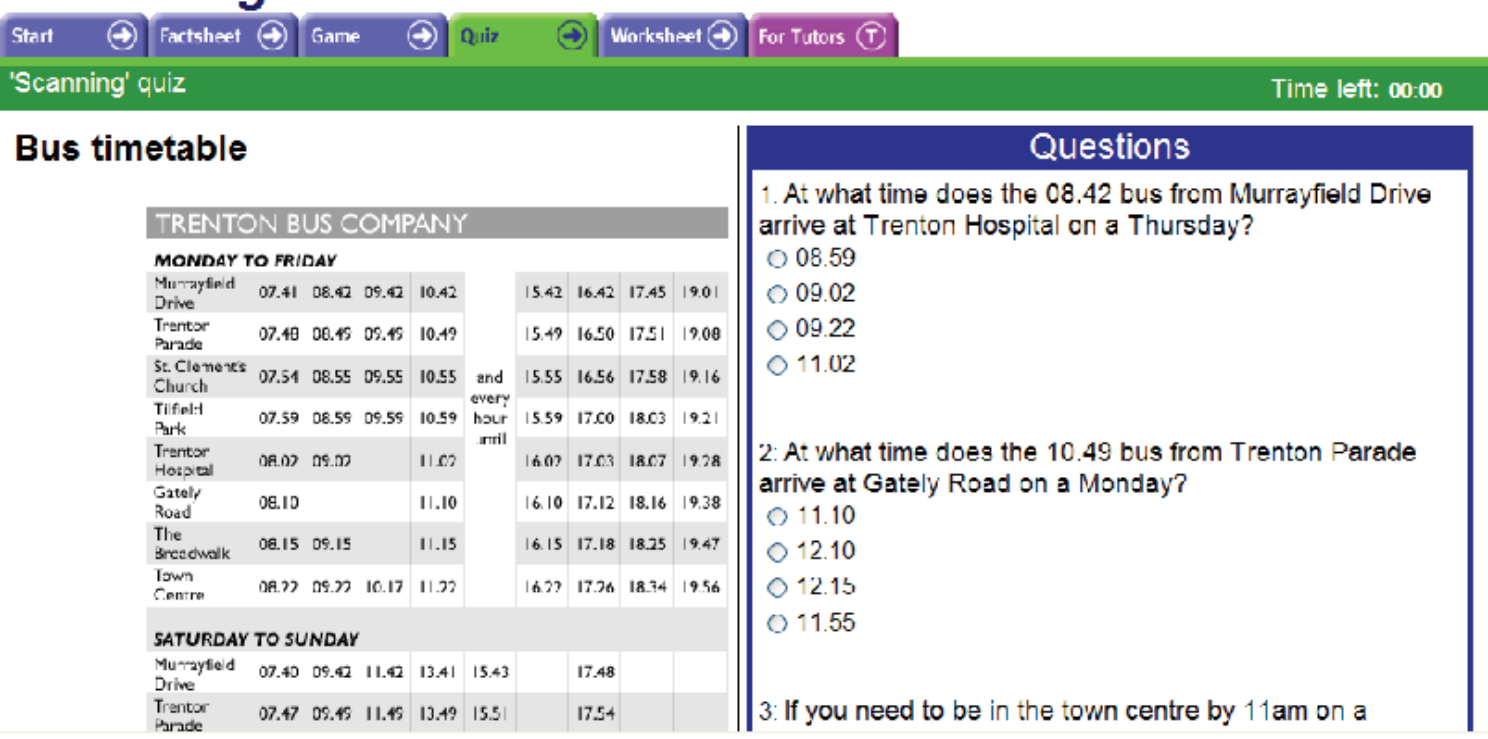

Figura 2 - Atividade de leitura - scanning com as questões de compreensão (bbc.co.uk/skillwise).

\section{Scanning}

\section{Stert $\Theta$ Factsheet $\Theta$ Game $\Theta$ Quiz $\Theta \mid$ Worksheet $(\rightarrow)$ For Tutors $(\mathrm{I}$}

\section{Bus timetable}

\begin{tabular}{|c|c|c|c|c|c|c|c|c|c|}
\hline \multicolumn{10}{|c|}{ TRENTON BUS COMPANY } \\
\hline \multicolumn{10}{|c|}{ MONDAY TO FRIDAY } \\
\hline $\begin{array}{l}\text { Mu ayfled } \\
\text { Drive }\end{array}$ & 07.41 & ถะ. 45 & (อ.. 4$)$ & 10.42 & \multirow{8}{*}{$\begin{array}{l}\text { and } \\
\text { avery } \\
\text { harir } \\
\text { sndil }\end{array}$} & $154 ?$ & 16.42 & 17.45 & 1901 \\
\hline $\begin{array}{l}\text { Trantor } \\
\text { Parathr }\end{array}$ & 07.48 & 08.45 & 09.45 & 10.49 & & 15.49 & 16.50 & 17.51 & 19.08 \\
\hline $\begin{array}{l}\text { St. Cle mearis } \\
\text { Chureh }\end{array}$ & 07.54 & 08.55 & 09.55 & 10.55 & & 15.55 & 16.56 & 17.58 & 19.16 \\
\hline $\begin{array}{l}\text { Tiffeld } \\
\text { arks }\end{array}$ & 07.59 & n8. 59 & 09.59 & 10.59 & & 1559 & 1750 & $18 \times 3$ & 19.31 \\
\hline $\begin{array}{l}\text { Trentor } \\
\text { Hestpral }\end{array}$ & 06.02 & 08.02 & & 11.02 & & 16.02 & 17.03 & 18.07 & 19.28 \\
\hline $\begin{array}{l}\text { Gatrly } \\
\text { Road }\end{array}$ & 08.10 & & & 11.10 & & 16.10 & 17.12 & 18.16 & 19.38 \\
\hline $\begin{array}{l}\text { The } \\
\text { Breacivalk }\end{array}$ & of. 15 & ns. 15 & & 11.15 & & 1615 & 17.18 & 18.75 & 19.47 \\
\hline $\begin{array}{l}\text { Town } \\
\text { Centre }\end{array}$ & 00.22 & 08.22 & 10.17 & 11.22 & & 16.22 & 17.26 & 18.34 & 19.56 \\
\hline \multicolumn{10}{|c|}{ SATURDAY TO SUNDAY } \\
\hline $\begin{array}{l}\text { Mu-tayfind } \\
\text { Drive }\end{array}$ & $07.4 \mathrm{D}$ & ns. 4 & $11.4)$ & 13.41 & 15.43 & & 17.48 & & \\
\hline $\begin{array}{l}\text { Trentor } \\
\text { Parade }\end{array}$ & 07.47 & 09.45 & 11.45 & 13.49 & |5.5. & & 17.54 & & \\
\hline 5t. Cle nerss & 07.53 & 09.55 & 11.55 & 13.55 & 15.57 & & 18.00 & & \\
\hline
\end{tabular}

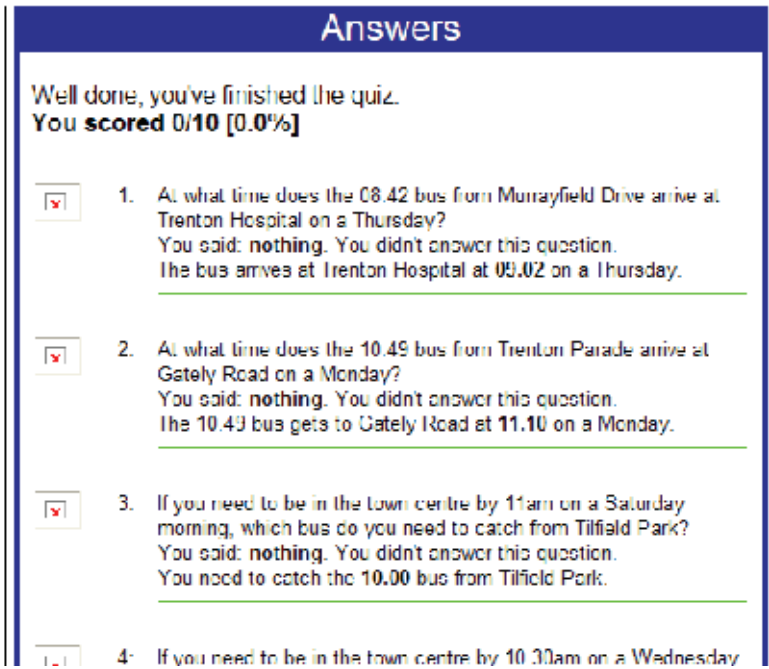

Figura 3 - Feedback de uma atividade de scanning (bbc.co.uk/skillwise).

ARAÚJO - Computadores e ensino de línguas estrangeiras... 
A instrução para realizar a atividade nem sempre é clara e objetiva e, às vezes, não há instrução na atividade (a compreensão de textos no site da BBC é um exemplo; ver figura 2), o que se justifica, talvez, pelo fato de a maioria das atividades apresentarem questões de compreensão em formato de múltipla escolha, o que pressupõe que os alunos já estão familiarizados com este tipo de exercício em materiais impressos.

Quanto à interatividade, os websites na grande maioria mostram que as atividades de leitura/escrita oportunizam apenas a interação homem-máquina. Não há instrução para os aprendizes discutirem ou analisarem o texto on-line. Quando muito, o professor pode tomar a iniciativa de realizar a interação professor-aluno. Com relação à usabilidade, as atividades são fáceis de acessar e navegar e não se percebe uma carga excessiva de informação visual ou verbal que deixe o aluno confuso e perdido, sem saber que caminho trilhar.

Nos sites, as poucas atividades de escrita têm o objetivo de consolidar vocabulário, gramática, ou testar a compreensão de textos. Isto revela que a escrita é a habilidade negligenciada no ensino de língua inglesa, tanto nos materiais impressos quanto nos on-line. As atividades, na grande maioria, têm o formato de preenchimento de lacunas. $\mathrm{O}$ que significa que os aprendizes de língua estrangeira ainda continuam a realizar atividades que não têm o objetivo da comunicação, mas apenas de consolidar a aprendizagem de aspectos gramaticais. Estas atividades não ajudam o aluno a resolver problemas, a se expressar criticamente e desenvolver a criatividade. $O$ diferencial destes exercícios relativamente àqueles que se apresentam nos livros didáticos adotados em sala de aula é que o aluno tem o feedback imediato, seja em questões objetivas seja em questões discursivas. $\mathrm{O}$ aluno pode checar os erros cometidos e reler o texto e tentar responder corretamente às questões. Poucos sites realmente apresentam atividades de escrita (o da BBC, towerofenglish.com, better-english.com, johnsesl.com, englishzone.com) que estimulam os aprendizes a produzirem textos, responderem games, puzzles, como também a escreverem mensagens para enviar por e-mail, participar de fóruns de discussão, blogs e pen-pals inserindo os internautas na prática de novos gêneros emergentes on-line. Nos sites que oportunizam escrever textos on-line requer-se do aprendizusuário o uso de uma senha para responder a atividade, considerando que essa atividade não é gratuita e é enviada a um professor virtual para 


\section{4}

correção. No site da BBC, as atividades de escrita se restringem a trabalhar o parágrafo, a escrever estórias, a escrever alguns gêneros e exercícos de palavras transicionais (coesivas). Na página, o link para atividades de escrita de parágrafos tem por objetivo a escrita de pequenas composições que variam desde descrições, postais, até estórias, possibilitando praticar a escrita. Se o aprendiz desejar, o site sugere que o aprendiz pode responder o exercício em uma folha impressa.

Outro exemplo que merece ser analisado é o site da Reading Matrix, que, apesar de ter objetivo específico e explorar apenas a habilidade de leitura, tem poucos links e apresenta a atividade de leitura em três níveis: elementar, intermediário e avançado. O aluno clica no nível desejado e descobre uma lista de tópicos. Ele então clica em dos tópicos que o leva ao texto escolhido para ser lido. Após a leitura do texto, o aluno clica na página de perguntas e respostas que mostrará em scores quantas perguntas de compreensão ele acertou. No mesmo estilo, o site english-zone.com também traz atividades de aprendizagem de língua inglesa agrupadas por zona, e uma delas é leitura. A zona de leitura traz atividades de leitura em vários níveis com questões de comprensão de múltipla escolha e as respostas para serem checadas no final da atividade, como mostra o exemplo na figura 4.

No exemplo extraído do site english-zone.com mostra-se uma atividade de leitura em que o texto e as questões de compreensão são para nível iniciante. O texto se constitui nas informações do remetente e destinatário em um envelope de carta, e o aluno deverá compreender as informações apresentadas no envelope ao responder as perguntas de compreensão, limitadas ao número de dez, e em formato de múltipla escolha, em que o aluno clica para ver as opções de resposta, selecionando apenas a resposta correta. Ao terminar de responder às perguntas, o aluno clica em um botão Check Answers para conferir as respostas corretas. Se o aprendiz erra todas as respostas, ele/a pode repetir a atividade e tentar acertar as respostas por ensaio e erro. No mesmo site, as atividades de escrita trazem apenas explicações e exemplos de como se escrever diferentes tipos de parágrafos, estórias e um link para escrever uma tarefa e enviar a um professor virtual. Este link só pode ser acessado com uma senha, o que exige um cadastro do alunousuário.

ARAÚJO - Computadores e ensino de línguas estrangeiras... 
READING AN ENVELOPE 1

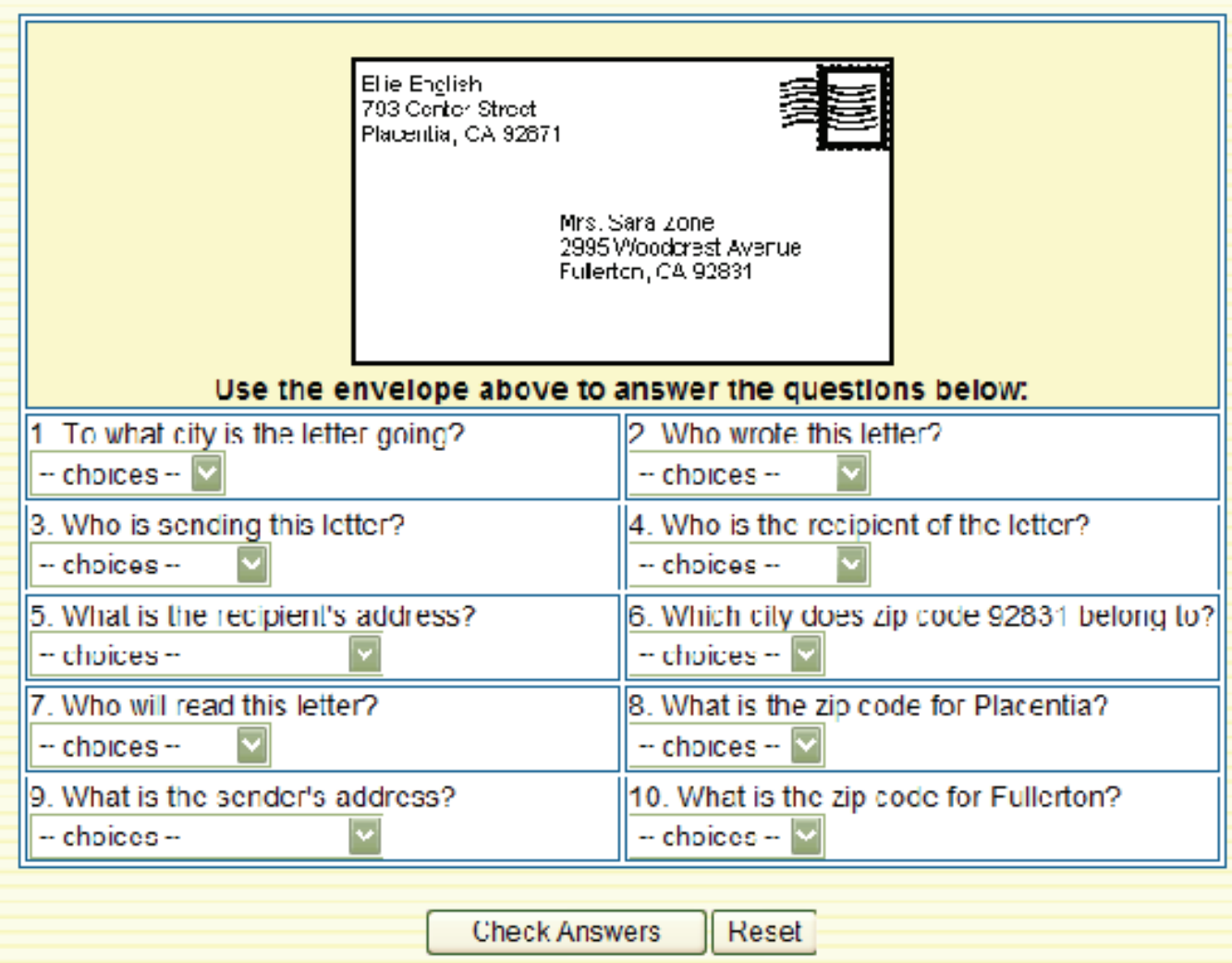

Figura 4 - Atividade de leitura para iniciantes (fonte: site Englishzone.com).

A maneira como os sites em análise são planejados possibilita que os aprendizes tanto acessem e explorem todos os links na sala de aula monitorados pelo professor, quanto realizem as atividades em casa ou outro lugar sem necessidade de orientação do professor, se eles tiverem domínio de língua e autonomia desenvolvidos. Ao avaliar os quinze sites com relação aos critérios já comentados, constatamos que 11 atendem a pelo menos 5 dos 8 critérios, podendo ser considerados como sites que oferecem atividades adequadas para o desenvolvimento das habilidades de leitura e escrita, embora planejados em um paradigma epistemologicamente behaviorista. Os quatro websites restantes englishpage, englishbaby.com, english-at-home.com e better-english.com - não atendem à maioria dos critérios, sendo que os links destes sites levam a outras páginas que em geral são revistas ou jornais reais, e nenhuma proposta de atividade de compreensão de textos. 
Estudiosos têm advogado que a aprendizagem mediada por computador se caracteriza por ser mais dinâmica, participativa, descentralizada da figura do professor e baseada na independência, na autonomia, nas necessidades e interesses imediatos de cada um dos alunos letrados digitalmente e usuários das tecnologias e comunicação digital (SINGHAL, 1997; MELONI, 1998). Com base neste pensamento, os argumentos para se integrar as fontes da Internet em um contexto de ensino-aprendizagem de língua estrangeira são cada vez mais fortes e podem estar associados ao grau de controle que professor e aluno podem ter de seu processo de ensino-aprendizagem, isto é, ao fato da visão que ambos, professor e aluno, compartilham sobre leitura e escrita, de como ambos abordam o texto para leitura, que estratégias eles empregam para compreender e produzir textos no contexto de ensino mediado por computador.

A análise de websites aponta para a necessidade de se repensar:

a) novos paradigmas que atendam às características do novo contexto e dos usuários;

b) o formato de atividades que oportunizem não só o aprendizado da língua, como também as formas de interação entre interlocutores em contextos de comunicação reais e autênticas; e

c) o papel do professor no ambiente mediado por computador.

No que diz respeito ao papel do professor no contexto das novas tecnologias, questiona-se até que ponto o professor de língua está preparado para exercer seu papel neste novo contexto de ensinoaprendizagem. Sabe-se que o professor precisa se conscientizar e se integrar às exigências da sociedade pós-moderna, adotando uma nova postura e práticas pedagógicas. Uma das exigências é que o professor deve ter competência para usar o computador e os recursos da Internet, isto é, ser letrado digitalmente, para poder acompanhar os alunos no seu processo de aprendizagem da língua estrangeira, mas também para poder estabelecer novas formas de ação pedagógica para a utilização da linguagem verbal e não verbal (XAVIER, 2005). Nesse novo contexto, o professor precisa ser pesquisador, gestor, mediador e motivador de aprendizagem. 
Como as análises de websites com foco nas atividades propostas para leitura e escrita nem sempre são motivantes como input para a aprendizagem de línguas, cabe ao professor ter uma formação pedagógica, cultural e tecnológica específica para saber selecionar atividades realmente adequadas para possibilitar um ensinoaprendizagem mais interativo e eficaz. Lee (2002, on-line) sugere que os professores considerem quatro passos quando planejando atividades na Internet:

a) estabelecer objetivos (quais são os própositos para usar a Internet?);

b) métodos (que métodos subjazem às atividades educacionais colaborativas, centradas no aprendiz - que podem ser incorporadas nas atividades da internet?);

c) procedimentos/atividades (como e quais atividades os estudantes precisam realizar?); e

d) avaliação (como medir a aprendizagem dos alunos?).

Com base nesses passos e contando com uma formação continuada específica sobre os processos de integração da tecnologia à ação pedagógica dos professores, estes podem planejar projetos em que envolvam os alunos em atividades colaborativas e que reforcem as habilidades de leitura e escrita, como por exemplo, estimular os estudantes a escreverem textos tendo por base um número de matérias informativas da web em língua estrangeira de estudo (inglês, espanhol, francês), enviar e-mails ou postar mensagens em blogs discutindo algum tópico de sala de aula.

\section{COMENTÁRIOS FINAIS}

Sem dúvida alguma, reconhece-se que a internet é uma ferramenta útil para o desenvolvimento do ensino e aprendizagem da L2 ou LE. Os aprendizes podem interagir e negociar sentidos na língua estrangeira com audiência autêntica e real, terem maior envolvimento nas tarefas e desenvolverem autonomia. As atividades na web não somente ajudam os 
aprendizes a desenvolverem suas habilidades linguísticas, isto é, letramento na segunda língua, por meio do estudo de textos autênticos, como também a explorar as culturas da língua-alvo via interação com uma diversidade de pessoas e lugares disponíveis na internet ou via interação com falantes nativos através de e-mail, chats, blogs.

A análise dos websites educacionais revelou que as atividades propostas não são desafiantes e são ainda distantes das ações humanas nas esferas comunicativas do cotidiano. Neste estudo, a análise das atividades aponta para a necessidade de se repensar as atividades de leitura e escrita, no sentido de torná-las mais comunicativas e interativas, para estimular no aluno o interesse pela aprendizagem da língua estrangeira e levá-los a desenvolver suas próprias estratégias de aprendizagem e autonomia. Neste aspecto, os professores de línguas estrangeiras podem ajudar quando integram a internet em suas aulas e exploram todas as possibilidades para a aprendizagem de línguas oportunizando o uso de materiais autênticos, comunicação dinâmica e situações mais reais. No entanto, muitas pesquisas ainda precisam ser realizadas para se conhecer as práticas pedagógicas com novas tecnologias na aprendizagem de língua estrangeira em contextos mediados por computador e o impacto dessa aprendizagem na vida real dos alunos.

\section{REFERÊNCIAS}

BARNES, A; MURRAY, L. Beyond the "wow" factor - evaluating multimedia language learning software from a pedagogical viewpoint. System, Pergamon Press, v. 26, p. 249-259, 1998.

BARTON, D.; HAMILTON, M. Local literacies: reading and writing in one community. London: Routledge, 1998.

BAX, S. CALL - past, present and future. System, v. 31, Pergamon Press, p. 13-28, 2003.

BRANDL, K. Integrating Internet-based reading material into the foreign language curriculum: from teacher- to student-centered approaches. Language learning \& technology, v. 6, n. 3, p. 87-107, 2002. 
CASTANHEIRA, M. L.; GREEN, J.; DIXON, C. N. Práticas de letramento em sala de aula: uma análise de ações letradas como construção social. Revista portuguesa de educação, v. 20, n. 2, p. 7-38, 2007.

FREIRE, M. et al. Roteiro para avaliação de cursos online de idiomas. In: COLLINS, H.; FERREIRA, A. (Orgs.). Relatos de experiência de ensino e aprendizagem de línguas na internet. São Paulo: Mercado das Letras, 2004. p. 245-276.

KASPER, L. F. New technologies, new literacies: focus discipline research and ESL learning communities. Language learning and technology, v. 4, n. 2, p. 105-128, 2000.

KELLY, C. Guidelines for designing a good ESL web site for ESL students. The internet TESL journal, v. 6, n. 3, 2000. Disponível em: <http://iteslj.org/ Articles/Kelly-Guidelines.html>. Acesso em: 10 set. 2005>. KRESS, G. Literacy in the new media age. London: Routledge, 2003. LEE, L. Using internet to enhance foreign language teaching and learning. Disponível em: <http://www.unh.edu/spanish/lina/ internet1.html/> Acesso em: 29 mar. 2002.

MELONI, C. The Internet in the classroom: a valuable tool and resource for ESL/EFL teachers. ESL magazine, 1998. Disponível em: < http://www. eslmag.com/Article.htm>.

MOOTE, S. Evaluation considerations for online ESL courses. The internet TESL journal, v. VIII, n. 3, March 2002. Disponível em: <http://itselj. org/ÁrticleMoote.Evaluation.html>. Acesso em: 17 mar. 2003.

PAIVA, V. L. M. O. Feedback em ambiente virtual. Disponível em: <http://www.veramenzes.com/feedback.htm>. Acesso em: 28 set. 2005.

RICHARDS, J. C. The role and design of instructional materials: curriculum development in language teaching. Cambridge: Cambridge University Press, 2001. p. 251-285.

ROMÁN, E. Web-based instructional environments: tools and techniques for effective second language acquisitions. International journal of English studies, v. 2, n.1, p. 31-58, 2002.

SHETZER, H.; WARSCHAUER, M. An electronic literacy approach to network-based language learning. In: WARSCHAUER, M.; KERN, R. (Eds.). Network-based language teaching: concepts and practice. Cambridge: Cambridge University Press, 2000. p. 171-185. 
SINGHAL, M. The Internet and foreign language education: benefits and challenges. The internet TESL journal, v. 3, n. 6, 1997. Disponível em: $<$ http://iteslj.org/Articles/Singhal-Internet.html>.

SMITH, A. G. Testing the surf: criteria for evaluating internet information resources. 1997. Disponível em: <http://info.lib.uh.edu/ pr/v8/n3/smit8n3.html>. Acesso em: 16 out. 2004.

SNYDER, I. Literacy and technology studies: past, present, future. Australian educational researcher, v. 27, n. 2, p. 97-119, 2000.

SOUZA, R. A. Um olhar panorâmico sobre a aprendizagem de línguas mediada pelo computador: dos drills ao sociointeracionismo. Fragmentos, Florianópolis, n. 26, p. 73-86, jan/jun. 2004.

STAPLETON, P.; HELMS-PARK, R. Evaluating web sources in an EAP course: introducing a multi-trait instrument for feedback and assessment.

English for specific purposes, v. 25, p. 438-455, 2006.

STREET, B. Literacy in theory and practice. Cambridge: Cambridge University Press, 1984.

WARSHAUER, M. Computer-mediated collaborative learning: theory and practice. Modern language journal, n. 81, p. 470-481, 1997.

XAVIER, A. C. Letramento digital e ensino. In: SANTOS, C. F.; MENDONÇA, M. (Orgs.). Alfabetização e letramento: conceitos e relações. Belo Horizonte: Autêntica, 2005. p. 133-148.

ZORKO, V. Designing web-based multimedia material. IATEFL Poland computer sig journal, 2007. Disponível em: < http://www.iatefl. org.pl/call/j_web27.htm>. Acesso em: 13 jan. 2008.

Recebido em 25/01/09. Aprovado em 15/07/09.

Title: Computers and foreign language teaching: an analysis of instructional websites Author: Antonia Dilamar Araújo

Abstract: This article has the aim of examining and reflecting on instructional activities for the development of reading and writing skills available in websites on the Internet that can be used in classrooms as supplement for teaching English language. Based on defined criteria by experts who study new technologies applied to education, we intended to evaluate the quality of instructional web materials. Twenty-five websites were selected in English, but only fifteen were analyzed in detail regarding reading and writing activities. The results reveal that there is no great variety of reading and writing 
activities in websites as well as there is no great difference between the proposed activities in educational websites and those introduced in printed textbooks.

Keywords: internet; educational websites; English language teaching.

Titre: Ordinateurs et enseignement de langues étrangères: une analyse de websites instructionnels

Auteur: Antonia Dilamar Araújo

Résumé: Cet article a comme objectif celui d'examiner et réfléchir sur les activités proposées pour le développement des habiletés de lecture et écriture disponibles dans des wesites sur Internet et qui peuvent être employées comme complément de l'enseignement présentiel en salle de classe de langue anglaise. Ayant pour base des critères établis par des studieux en nouvelles technologies apliquées à l'éducation, on a voulu évaluer la qualité de ces matériaux instructionnels. Parmi 25 websites en langue anglaise sélectionnés, 15 furent analysés en détail avec focalisation dans les activités de lecture et écriture. Les résultats dévoilent qu'il y a peu de variété en ce qui concerne les activités de lecture et écriture dans les matériels du web et qu'il n'y a pas de différences entre les propositions d'activités des websites éducationnels et celles présentées dans les livres didactiques imprimes.

Mots-clés: internet; sites éducationnels; matériel didactique; enseigenement de langue anglaise.

Título: Computadores y enseñanza de lenguas extranjeras: un análisis de sitios instruccionales

Autor: Antonia Dilamar Araújo

Resumen: Este artículo tiene por objetivo examinar y reflexionar sobre las actividades propuestas para el desarrollo de las habilidades de lectura y escrita disponibles en sitios en la Internet y que pueden ser usadas como complemento de la enseñanza presencial en sala de clase de lengua inglesa. Con base en criterios establecidos por estudiosos de nuevas tecnologías aplicadas a la educación, se pretendió evaluar la calidad de esos materiales instruccionales. De 25 sitios en lengua inglesa seleccionados, 15 fueron analizados detalladamente con foco en las actividades de lectura y escrita. Los resultados revelan que hay poca variedad de las actividades de lectura y escrita en los materiales de la Web y que no hay diferencias entre las propuestas de actividades de los sitios educacionales y las presentadas en los libros didácticos impresos.

Palabras-clave: internet; sitios educacionales; material didáctico; enseñanza de lengua inglesa. 